\title{
MEDIDAS AGREGADAS DE POBREZA ABSOLUTA: A PROPOSTA DE SEN E OS DESENVOLVIMENTOS SUBSEQÜENTES
}

\author{
Maurício Costa Romão*
}

\section{Resumo}

O objetivo deste trabalho é mostrar os desenvolvimentos subsequentes do exercício agregativo da pobreza, a partir da medida de pobreza sugerida por Amartya Sen em 1976. Utilizando dados da PNAD e dos Censos Demográficos, são feitas estimativas de alguns dos princípais índices para o Brasil, como forma de ilustrar a aplicação desses índices.

\begin{abstract}
The objetive of this paper is to show the main developinent in the specilized literature on poverty related to the seminal work of Amartya Sen in aggregate measures of poverty. After reviewing the principal contributions on the subject, the text uses empirical data from Brazil to illustrate the application of the best known indices of poverty.
\end{abstract}

\section{Introdução.}

Os principais trabalhos de Amartya Sen sobre pobreza, escritos por volta da segunda metade dos anos setenta (Sen 1978, 1978a, 1979, 1980, 1981), marcaram definitivamente a literatura sobre o assunto, em particular no que tange aos problemas relativos à mensuração da pobreza. Desses trabalhos, o de 1976 se constitui na referência maior, não só pelo pioneirismo no tratamento sistemático do exercício agregativo da pobreza mas, sobretudo, pelo rigor lógico-teórico, a par

\footnotetext{
*Professor do Programa de Pós-Graduação em Economia (PIMES) do Departamento de Economia da Universidade Federal de Pernambuco. O autor agradece a Rodolfo Hoffmann pela paciência com que tem acompanhado a preparaçāo deste estudo, apontando falhas e sugerindo modificaçōes. Esses agradecimentos são extensivos a dois pareceristas desta Revista. Desnecessário dizer que eles estão isentos dos erros remanescentes.
}

\begin{tabular}{llll}
\hline R. de Economietria & Rio de Janeiro v. 13, no 1, pp.41-78 abril 1993 \\
\hline
\end{tabular}


da elegância, com que o autor desenvolve seu raciocínio e propõe um novo - e hoje consagrado - índice de pobreza. ${ }^{1}$

A partir desse marco referencial, inúmeros estudos emergiram trazendo sugestões alternativas à proposta original de Sen. propósito que animou a feitura do presente trabalho foi exatamente o de mostrar os subseqüentes desenvolvimentos do exercício agregativo da pobreza em torno da medida sugerida por Sen. O intuito é, pois, muito modesto e não pretende ir além da tentativa de sistematizar um volume relativamente amplo de discussões sobre o assunto, o qual se encontra espraiado e fragmentado em várias contribuições.

\section{A mensuração da pobreza.}

Num sentido geral, pode-se considerar que a mensuração da pobreza consiste em duas operações distintas (Sen 1976, 1978, 1979): a) identificação (quem são os pobres?); b) agregação (como combinar as características de pobreza de diferentes pessoas numa medida agregada?).

O processo de identificação - que logicamente precede o de agregação - resume-se em separar os pobres dos não-pobres, o que pode ser feito de várias maneiras, cada uma das quais constituindo uma diferente interpretação do fenômeno. Já o exercício agregativo busca expressar as características de pobreza de distintas pessoas ou grupos em um único indicador ou índice. ${ }^{2}$

Os critérios usados para identificar os pobres podem ser de caráter objetivo ou subjetivo. Os do primeiro tipo são aqueles que se baseiam em certos aspectos objetivos relacionados com a situação dos indivíduos, tais como renda, tamanho da familia, situação ocupacional, habitação etc. Já os do segundo tipo, aqueles de natureza subjetiva, dizem respeito a opiniões ou sentimentos das pessoas sobre

\footnotetext{
${ }^{1} \hat{E}$ oportuno registrar que em um outro trabalho anterior, Sen (1973) já havia esboçado suas principais idéias sobre os problemas de mensuraçāo da pobreza, chegando quase a dar forma ao índice que mais tarde o consagraria.

${ }^{2}$ Obviamente o procedimento de expressar de forma unidimensional a enorme gama de características que permeia a noçāo da pobreza implica um reducionismo naturalmente forte, mas inevitável se se pretende obter resultados quantitativos.
} 
quais deveriam ser os padrões mínimos de satisfação das necessidades dos indivíduos. ${ }^{3}$

O critério objetivo envolve, pelo menos, duas variantes operacionais importantes, de resto já consagradas na literatura: aquela que enfoca a pobreza do ponto de vista relativo e aquela que a considera apenas do ângulo absoluto.

A conceituação da pobreza sob o prisma relativo enfatiza a idéia de comparação situacional do indivíduo em termos da posição que ocupa na sociedade com respeito a seus semelhantes. Nota-se que a percepção da pobreza como conceito relativo se aproxima bastante da desigualdade na distribuição de renda. A pobreza é interpretada em relação ao padrão de vida vigente na sociedade: os pobres são os que se situam na camada inferior da distribuição de renda em comparação com os membros melhor aquinhoados da sociedade nessa distribuição.

Já a percepção da pobreza como um conceito absoluto implica o estabelecimento de padrões mínimos de necessidade, ou níveis de subsistência, abaixo dos quais as pessoas são consideradas pobres. $O$ padrão de vida mínimo (em termos de requisitos nutricionais, moradia, vestuário etc.) em geral é avaliado a preços de mercado e a renda necessária para custeá-lo é calculada.

\subsection{As medidas convencionais.}

Definido qual o conceito operacional de pobreza mais pertinente para o estudo a ser empreendido - e no presente trabalho o objeto de investigação baseia-se no conceito de pobreza absoluta - o próximo passo é determinar a linha de pobreza absoluta.

Calculada a linha de pobreza, ainda resta a questão de compatibilizar os diferentes graus de pobreza dessas pessoas que foram rotuladas de pobres, quer dizer, como expressar as características de pobreza de um dado contingente heterogêneo? Problemas de natureza operacional forçam a adoção de certos indicadores agregados, os

\footnotetext{
${ }^{3} \mathrm{~A}$ assertiva de Orshansky (1969, p. 37) expressa bem os juízos de valor que circundam a noçāo subjetiva: "a pobreza, como a beleza, está no olhar de quem a vê". A literatura recente registra grande crescimento de estudos que aplicam o método subjetivo, principalmente em países europeus. Vide, por exemplo, Van Praag, Goedhart \& Kapteyn (1979), Hagenaars (1986), Hagenaars \& De Vos (1987), Kapteyn, Kooreman \& Willemse (1987).
} 
quais, obviamente, não conseguem captar, in totum, a intensidade de pobreza sofrida por aqueles que se encontram aquém do mínimo de subsistência. Não obstante essas dificuldades, o índice proposto por Sen, como se verá mais adiante, parece não sofrer de alguns defeitos característicos das medidas padrão até recentemente usadas no exercício agregativo. Tanto assim é que seu uso generalizou-se progressivamente na literatura, seja em análises empíricas (Bhatty, 1974; Anand 1977; Szal 1977; Dutta 1978; Ahluwalia 1978; Thomas 1978, 1982; Altimir 1978; Van Ginneken 1980; Kakwani 1980; Fishlow 1980; Fields 1980; Prado 1980, 1981; da Mata 1979; Hoffmann 1984, 1985, 1990; CEPAL 1985; Jaguaribe et alli 1986; Hagenaars 1986; Greer \& Thorbecke 1986; Besley \& Kanbur 1988; Rocha 1990; Ahmed, Khan \& Sampath 1991; Rodgers \& Rodgers 1991), seja dando margem ao aparecimento de formulações alternativas (Bhatty 1974; Alamgir 1975; Anand 1977; Hamada e Takayama 1978; Thon 1979; Blackorby e Donaldson 1980; Kakwani 1980; Foster, Greer \& Torbecke (sem data); Clark, Hemming \& Ulph 1981, Pyatt 1987; Rodgers \& Rodgers 1991). ${ }^{4}$ Antes, porém, de abordar o índice de Sen, é necessário fazer uma breve revisão das medidas padrão a que aludimos acima.

Para medir o grau de pobreza de uma determinada comunidade, dois índices têm sido usados em larga escala: o índice de "incidência de pobreza" e o índice de "insuficiência de renda", ou de "defasagem de renda". O primeiro é simplesmente a proporção da população que se encontra abaixo da linha de pobreza. O segundo mede a deficiência, ou defesagem, agregada de renda de todos os pobres em relação ao valor monetário da linha de pobreza.

Assim, se $q$ é o número de pobres e $N$ é a população total, a incidência de pobreza $H$, é simplesmente:

$$
H=\frac{q}{N}
$$

Definido $Z$ como a linha de pobreza, dada exogenamente, e $g_{i}$ como a defasagem de renda do indivíduo $i$, isto é:

$$
g_{i}=Z-Y_{i}
$$

${ }^{4}$ Vide Sen (1981, p. 37) para outras referências sobre aplicações e variantes do seu índice original. 
onde $y_{i}$ é o nível de renda do $i$-ésimo do indivíduo, o índice de defasagem de renda, $T$, é dado por:

$$
T=\sum_{i=1}^{q} g_{i}=q(Z-m)
$$

Onde $m$ é a renda média dos pobres. Covenientemente normalizado, $T$ pode ser expresso em termos percentuais, per capita:

$$
I=\frac{T}{q Z}=\frac{Z-m}{Z}
$$

Reescrito desta forma, o índice de insuficiência de renda pode ser interpretado como a percentagem da renda média dos pobres que fica aquém do nível de pobreza $\mathrm{Z}$.

Sen $(1973,1976,1978,1979)$ criticou essas duas medidas usando os seguintes argumentos:

(a) $O$ índice $H$ não leva em consideração os montantes das rendas (dos pobres) que ficam aquém do mínimo de subsistência. Ou seja, o índice é totalmente insensível para o "grau" de pobreza dos pobres, não captando quão perto ou distante alguém possa estar da linha de pobreza.

(b) $O$ índice de insuficiência de renda, $T$, apenas retrata o montante de renda que elevaria os pobres ao nível da linha de subsistência, enquanto $I$ é completamente insensível ao número de pobres envolvidos no processo agregativo. ${ }^{5}$

(c) Os índices $H$ e $T$ (ou seu valor normalizado $I$ ) não levam em consideração a distribuição de renda entre os pobres. Particularmente, as duas medidas são insensíveis à transferência de renda, se o número de pobres não se modifica.

Para corrigir essas deficiências, Sen desenvolveu uma medida de pobreza em que o número de pobres, o montante de renda aquém do mínimo de subsistência e a desigualdade de renda entre os pobres são incorporados num só índice. Para tanto, originariamente empregou uma abordagem axiomática, usando uma estrutura ordinal de

\footnotetext{
${ }^{5}$ Dada a renda média dos pobres, o valor de $I$ nāo se altera quando varia o número de pobres.
} 
bem-estar individual (Sen 1973, 1976). Mas, nos seus mais recentes trabalhos sobre o assunto (Sen 1978, 1979), o autor abandona o uso de comparações individuais de bem-estar e mostra que seu índice pode ser derivado com o emprego das noções socialmente concretas e objetivas de "privação relativa" e "privação absoluta", ambas fundamentais para a conceituação de pobreza. ${ }^{6}$ Vejamos como se dá esta derivação.

\subsection{O índice de pobreza de Sen.}

Consideremos um vetor de rendas $Y=\left(Y_{1}, Y_{2}, \cdots, Y_{N}\right)$ e suponhamos que $Y_{1}<Y_{2}<\cdots<Y_{N}$. Chamemos de $S(x)$ o conjunto de pessoas, numa comunidade $S$ de $N$ pessoas, com rendas nãosuperiores a $x$. Se $Z$ é a linha de pobreza, então $S(Z)$ é o conjunto formado apenas por pessoas pobres. Sen (1976) propôs uma medida agregativa de pobreza, $P$, que é definida como uma soma ponderada, normalizada, de defasagens individuais de renda $g_{i}$, no conjunto $S(Z)$ :

$$
P=A(Z, y) \sum_{i=1}^{q} g_{i} v_{i}(Z, y)
$$

onde $A(Z, y)$ é um parâmetro que depende da normalização escolhida e $v_{i}(Z, y)$ é um peso não-negativo na defasagem de renda $g_{i}$ do indivíduo $i$. Notemos que, por enquanto, a formulação apresentada em (1) está bem geral, posto que tanto os pesos $v_{1}$ quanto o parâmetro $A$ não estão especificados.

Tomando os níveis de renda das pessoas pobres e ordenando-os decrescentemente a partir do nível de subsistência $Z$, isto é, da renda mais alta para a renda mais baixa, denominemos a posição da $i$-ésima pessoa nessa ordenação de $R(i)$.

Seria natural, portanto, que a medida de pobreza que captasse tal ordenação devesse ponderar as defasagens de renda das pessoas numa relação direta, isto é, quanto maior fosse $R(i)$ maior deveria ser o correspondente peso $v_{i}$. Sen $(1978,1979)$, usa o seguinte axioma para estabelecer precisamente esta correspondência.

${ }^{6}$ Há uma extensa literatura tratando do conceito de pobreza. Vide Romāo (1982a, 1983, 1990) para algumas referências importantes. 
Axioma R (Ordenação de Privação Relativa): o peso $v_{i}$, associado com a insuficiência de renda $g_{i}$ do indivíduo $i$ é igual à colocação do mesmo indivíduo na ordenação de rendas entre os pobres, isto é: $v_{i}=R(i)$.

Este axioma define preliminarmente o sistema de pesos que deve ser utilizado na formulação (1). Observemos, entretanto, que há exatamente $(q-i+1)$ pessoas entre aquelas em $S(Z)$ com rendas, no mínimo, tão altas quanto a da pessoa $i$ e, portanto, o peso $v_{i}$ associado com a defasagem de renda $g_{i}$ da pessoa $i$ poderia ser dado por: $v_{i}=q-i+1$.

O axioma $R$ permite a apreensão da idéia de privação relativa de uma maneira bem simples e a ponderação proposta por Sen ressalta bem a prioridade que se deve dar aos menos favorecidos. ${ }^{7}$ Assim, o mais pobre dos indivíduos no spectrum de renda recebe o mais alto pelo possível, $q$, e o menos pobre recebe o mais baixo, isto é, um. Agora, a expressão (1) pode ser reescrita como:

$$
P=A(Z, y) \sum_{i=1}^{q} g_{i}(q-i+1)
$$

onde apenas o parâmetro $A$ ainda está indefinido.

Consideremos novamente a normalização efetuada no índice de insuficiência de renda $T$ :

$$
I=\frac{T}{q Z}=\frac{Z-m}{Z}
$$

Notemos que este índice também pode ser interpretado como o montante proporcional de privação absoluta de renda vis-à-vis $Z$. Interpretação semelhante pode ser dada ao índice de pobreza $H$, que pode ser visto como representando a proporção de pessoas em privação visà-vis $Z$. Conclui-se, portanto, que essas duas medidas captam, cada uma isoladamente, algum aspecto da privação absoluta dos pobres. Juntas, elas fornecem uma idéia bastante acurada da extensão da

\footnotetext{
${ }^{7}$ Esta prioridade, aliás, está refletida no famoso critério rawlsiano de justiça social em que o objetivo social deve ser o bem-estar dos mais pobres dos indivíduos [Rawls (1971)].
} 
pobreza em termos daquela noção, o que deu margem a Sen (1978, 1979) propor o seguinte axioma:

Axioma $A$ (Privação Absoluta Normalizada): se todos os pobres têm a mesma renda, então $P=H I$.

Pelo axioma $A$, a defasagem de renda $g_{i}$ será a mesma para todos os pobres em $S(Z)$, isto é, $g_{i}=g *$, o que modifica (2) da seguinte forma:

$$
P=A(Z, y) \sum_{i=1}^{q} g *(q-i+1)=A(Z, y) g *[q(q+1) / 2]
$$

Mas, ainda pelo mesmo axioma $A$, o índice de pobreza é dado por:

$$
P=H I
$$

Agora, o parâmetro $A$ pode ser completamente especificado quando as expressões (5) e (6) são comparadas: $A(Z, y)=2 /(q+1) N Z$. O índice de pobreza de Sen é então escrito como:

$$
P=\frac{2}{(q+1) N Z} \sum_{i=1}^{q}\left(Z-Y_{i}\right)(q-i+1)
$$

A expressão (6) pode ainda ser manipulada de forma a representar explicitamente o índice agregado de pobreza $P$, como uma função do índice de incidência de pobreza $H$, do índice de insuficiência de renda $I$ e do coeficiente de Gini $G_{P}$ entre os pobres. Para derivar tal formulação, comecemos por analisar o coeficiente de Gini.

Existem várias maneiras de se mensurar a desigualdade de renda de uma dada distribuição através do coeficiente de Gini. Kendall \& Stuart (1977, pp. 47-53), por exemplo, apresentam uma formulação baseada no coeficiente da diferença média.

$$
G_{P}=\frac{1}{2 q^{2} m} \sum_{i=1}^{q} \sum_{j=1}^{q}\left|Y_{i}-Y_{j}\right|
$$

onde $y_{i}$ é o nível de renda do $i$-ésimo indivíduo no conjunto dos pobres. Observemos, entretanto, que: $\left|Y_{i}-Y_{j}\right|=Y_{i}+Y_{j}-2 \mathrm{~min}$ 
$\left(Y_{i}, Y_{j}\right)$ o que implica:

$$
\begin{aligned}
\sum_{i=1}^{q} \sum_{j=1}^{q}\left|Y_{i}-Y_{j}\right| & =\sum_{i=1}^{q} \sum_{j=1}^{q}\left(Y_{i}+Y_{j}\right)-2 \sum_{i=1}^{q} \sum_{j=1}^{q} \min \left(Y_{i}, Y_{j}\right) \\
& =2 q \sum_{i=1}^{q} Y_{i}-2 \sum_{i=1}^{q} Y_{i}(2 q-2 i+1)
\end{aligned}
$$

de onde deriva a fórmula final de Sen para o índice de Gini (Sen 1976, p. 224):

$$
G_{P}=1+\frac{1}{q}-\frac{2}{q^{2} m} \sum_{i=1}^{q} Y_{i}(q-i+1)
$$

Fazendo uso da expressão (8) e da equação (6), obtém-se:

$$
P=H\left[1-(1-I)\left(1-\frac{q}{q+1} G_{P}\right)\right]
$$

Para valores de $q$ muito grandes, o termo $\frac{q}{q+1}$ aproxima-se da unidade e, portanto, (9) pode assumir a forma final sugerida por Sen para o índice de pobreza:

$$
P=H\left(I+(1-I) G_{P}\right]
$$

O índice de pobreza de Sen varia de zero a um, assumindo o valor zero quando todas as rendas são maiores que o nível de pobreza $Z$ e sendo igual a um quando todas as rendas forem zero.

É oportuno, a essas alturas, apresentar uma ilustração empírica envolvendo a equação (10), que é composta de quatro importantes índices relacionados com a mensuração da pobreza: $P, H, I$ e $G_{P}$. Antes, porém, convém discutir alguns aspectos metodológicos que permeiam as estimativas da linha de pobreza absoluta, já que, logicamente, só podemos aplicar (10) após a determinação da mencionada linha.

\subsection{O estabelecimento da linha de pobreza absoluta.}

Da feita que o conceito de pobreza absoluta é escolhido, surge, de pronto, uma indagação: quais são esses "níveis mínimos indispensáveis" ou essas "necessidades básicas" que a sociedade, através 
de seus valores, julga que sejam adequados para o desenvolvimento do indivíduo enquanto pessoa e partícipe de uma coletividade? A resposta a esta indagação não está isenta de dificuldades e implica necessariamente enveredar pelos meandros da arbitrariedade.

Em primeiro lugar, é fundamental definir o que é "necessidade" e já se instala uma enorme área de controvérsias. Depois, precisado o que se entende por necessidade é mister identificar quais das necessidades são consideradas básicas e indispensáveis e quais não o são, e novo campo de problemas emerge. A válvula de escape usualmente empregada é levada a efeito através de dois artifícios: o primeiro, estreitando o conceito de forma a incluir apenas as chamadas necessidades materiais; o segundo, elegendo arbritariamente um conjunto dessas necessidades materiais e postulando níveis mínimos considerados indispensáveis a serem satisfeitos. ${ }^{8}$ Uma vez decidido, finalmente, quais são as necessidades básicas, torna-se preciso calcular o custo monetário que é requerido para satisfazê-las. Tal custo é comumente denominado de linha de pobreza.

O traçado das linhas de pobreza a partir de considerações nutricionais tem um legado histórico que remonta ao início do presente século (Rowntree 1901). Sua popularidade como método resulta do fato de reportar-se à mais básica e essencial de todas as necessidades que é a alimentação. É senso comum que sem o atendimento dos requisitos nutricionais mínimos não se pode levar uma vida normal e salutar, consistente com os padrões de decência humana que a moral e os costumes estabelecem. Embora o critério biológico nem de longe elimine a arbitrariedade inerente ao conceito de pobreza, ${ }^{9}$ ainda assim seu emprego permite reduzir o grau dessa arbitrariedade, posto que se refere à nutrição, núcleo básico e essencial de todas as necessidades, sem a qual a vida inexiste.

\footnotetext{
${ }^{8}$ Exemplo característico de um elenco de necessidades inclui os seguintes grupos: alimentos, água, habitaçāo, vestuário, saúde, educaçāo, transporte, mobiliário, recreaçāo e seguro social (CEPAL 1985, P. 140; Pinera 1979, pp. 5-6).

${ }^{9}$ Como se sabe, os requisitos mínimos de nutrientes podem variar de pessoa para pessoa, de acordo com a composiçāo etária, sexo, tipo e local de atividade etc. Dai porque qualquer dieta mínima normativa que se estabeleça para uma dada comunidade ou grupo de pessoas encerra necessariamente um conteúdo de arbítrio que é inevitável.
} 
Mas, em que consiste a operacionalização do método? Em primeiro lugar, é necessário estimar-se os requerimentos energéticos e protéicos médios da comunidade. Para tanto, pode-se levar em conta, como recomendado no famoso estudo da FAO/OMS (1971), as necessidades mínimas de energia e proteína das pessoas, segundo sexo, idade, peso, grau de atividade física, estado de gravidez e qualidade protéica da dieta. A partir dos requisitos de nutrientes, estabelece-se a dieta mínima normativa correspondente a uma cesta de alimentos de baixo custo.

Determinada a cesta de alimentos com os elementos energéticos e protéicos ajustados aos requerimentos mínimos definidos, calculase, finalmente, o montante de recursos monetários que é necessário para sua aquisição. Tal montante ou custo corresponde ao que se denominou muito propriamente de linha de indigência.

Quanto a outras necessidades, um procedimento empírico largamente utilizado para estimar as despesas não-alimentares foi originalmente proposto por Orshansky (1965) e consiste em estabelecer uma relação normativa entre gastos com alimentação e gastos totais:

$$
\begin{aligned}
& \frac{\text { Gastos dos pobres com alimentação }}{\text { Gastos totais dos pobres }}=X \% \\
& \text { Custo da cesta básica } \times \frac{1}{x \%}=\text { linha de pobreza }
\end{aligned}
$$

\subsection{Algumas estimativas.}

O primeiro passo em direção ao cálculo da linha de pobreza absoluta para o Brasil foi o de dividir, seguindo a metodologia desenhada no texto, as necessidades básicas das pessoas em dois componentes: alimentação e outras necessidades.

$O$ custo da cesta de alimentos de que se lançou mão no presente trabalho foi obtido diretamente do estudo do Banco Mundial no Brasil (World Bank 1979) que, por sua vez, adota os padrões apropriados de nutrição recomendados pela Organização das Nações Unidas para Alimentação e Agricultura e pela Organização Mundial da Saúde. ${ }^{10}$

${ }^{10} \mathrm{O}$ estudo do Banco Mundial foi posteriormente editado em português, de forma resumida, por Knight \& Moran (1983). 
O custo da dieta adequada estimada neste estudo refere-se à média aritmética não-ponderada dos custos das dietas das 22 sub-regiōes do ENDEF estimados pelo Banco Mundial. Esta média, que correspondente ao custo anual per capita de uma dieta de aproximadamente 2.242 calorias, foi calculada em $\mathrm{Cr} \$ 5.116,36$ por ano, a preços de setembro de 1986. Em salários mínimos do mesmo mês e ano, o custo por pessoa dessa cesta de alimentos é equivalente a 6,363 salários mínimos anuais ou 0,530 mensais.

Valendo-se, mais uma vez, da pesquisa do ENDEF, que tem informações sobre despesas com alimentação e despesas correntes totais, foi possível estimar o percentual da renda total das familias pobres que é gasto com alimentação, o qual se situou em torno de $59,9 \%$. Esta percentagem corresponde aos gastos com alimentação das famílias situadas no primeiro intervalo de renda da pesquisa do ENDEF. Finalmente, multiplicando-se o custo da cesta básica (linha de indigência) pelo inverso do percentual encontrado, tem-se a linha de pobreza. A Tabela 1 mostra os achados das linhas de pobreza para o Brasil e Grandes Regiōes.

Para levar a efeito algumas estimativas que pudessem retratar o panorama atual e retrospectivos da magnitude da pobreza no Brasil, fez-se uso, de início, das publicaçōes de rendimentos das pessoas de 10 anos ou mais, com rendas positivas, a fim de localizar a linha divisória que separaria as pessoas pobres das não-pobres. ${ }^{11}$ Para tanto, utilizou-se as informações agregadas constantes dos Censos Demográficos de 1960, 1970 e 1980 e da Pesquisa Nacional por Amostra de Domicílio (PNAD) para os anos de 1983, 1986, 1987 e 1988.

A Tabela 2 perfila as medidas tratadas nas seções 2.1 e 2.2 e dão uma idéia da dimensão da pobreza no Brasil, em alguns anos selecionados. ${ }^{12}$

\footnotetext{
${ }^{11}$ Para os cômputos referentes às Grandes Regiōes, vide Romão (1990, 1991). A propósito, em correspondência privada, Rodolfo Hoffmann adverte que tais estimativas podem estar su perestimando a proporçāo de pobres na populaçāo em face do método de inter polaçāo utilizado. Ele sugere o uso de métodos mais avançados, como aqueles propostos por Cowel \& Metha (1982) e Hoffmann (1984a).

${ }^{12}$ Vide Romāo (1992) para uma análise da evoluçāo destas medidas no contexto do crescimento econômico brasileiro.
} 
Tabela 1.

Brasil e grandes regiôes: custo da dieta básica e linha de pobreza (em salários mínimos mensais de setembro de 1986)*

\begin{tabular}{ccc}
\hline Brasil e Grandes Regiōes & Custo da Dieta & Linha de Pobreza \\
\hline BRASIL & 0,5300 & 0,8847 \\
Centro.Oeste & 0,3729 & 0,7664 \\
Norte & 0,5330 & 0,9569 \\
Nordeste & 0,4937 & 0,7795 \\
Sudeste & 0,5929 & 0,9118 \\
Sul & 0,4559 & 0,7052 \\
\hline
\end{tabular}

Fonte: Estimativas a partir de dados básicos do Banco Mundial sobre dietas típicas de famílias brasileiras que apenas preenchem os requisitos calórico-protéicos baixos definidos pela FAO/OMS. Vide World Bank (1979), Knight \& Moran (1983) e FAO/OMS (1971). Os gastos nāo alimentares (diference entre a linha de pobreza e o custo da dieta) foram obtidos a partir da relacão normativa entre gastos com alimentação e gastos totais (coeficiente de Engel) das famílias pobres, localizadas no entorno de valor da dieta na distribuicão de despesas do ENDEF (1978). O coeficiente de Engel foi 59,9\% para o Brasil, $48,6 \%$ para o Centro-Oeste, $55,7 \%$ para o Norte, $63,3 \%$ para o Nordeste, $65,0 \%$ para o Sudeste e de $64,4 \%$ para o Sul.

* $\mathrm{O}$ defiator utilizado foi o IGP-FGV.

\subsection{Variações e alternativas.}

O impacto causado pelo aparecimento da medida proposta por Sen resultou, naturalmente, num estímulo para que surgissem medidas alternativas, todas elas, entretanto, emergiram preservando a estrutura básica do índice original. As novas medidas foram, sem exceção, oriundas de modificações em um dos dois, ou às vezes em ambos, axiomas propostos por Sen. Esse é o caso, por exemplo, do índice popularizado por Anand (1977, 1983), mas que já havia sido discutido antes pelo próprio Sen (Sen 1973a, 1976). Tal índice, que chamaremos mais adiante de $P_{a}$, resultou de uma ligeira modificação no axioma $A$, de forma que, quando todos os pobres tivessem a mesma renda, a medida de Sen se reduzisse ao índice de insuficiência 
Tabela 2.

Brasil: indices de pobreza (anos selecionados)

\begin{tabular}{ccccr}
\hline \multicolumn{5}{c}{ Conceitos } \\
\hline Anos & $\begin{array}{c}\text { Incidência } \\
\text { da pobreza } \\
(\mathrm{H})\end{array}$ & $\begin{array}{c}\text { Defasagem de } \\
\text { renda média } \\
(\mathrm{I})\end{array}$ & $\begin{array}{c}\text { Coef. Gini } \\
\text { dos pobres } \\
\left(G_{p}\right)\end{array}$ & $\begin{array}{r}\text { Indice } \\
\text { de Sen } \\
(\mathrm{P})\end{array}$ \\
\hline 1960 & 0,414 & 0,419 & 0,238 & 0,231 \\
1970 & 0,393 & 0,411 & 0,260 & 0,221 \\
1980 & 0,244 & 0,307 & 0,285 & 0,123 \\
1983 & 0,419 & 0,410 & 0,286 & 0,243 \\
1986 & 0,284 & 0,277 & 0,233 & 0,126 \\
1987 & 0,359 & 0,424 & 0,311 & 0,217 \\
1988 & 0,393 & 0,344 & 0,275 & 0,206 \\
\hline
\end{tabular}

Fonte: Censos Demográficos de 1960, 1970 e 1980 e PNADs de 1983, 1986, 1987 e 1988. Vide texto e Tabela 1.

de renda $T$, expresso como uma fração da renda total da comunidade (este novo índice é denominado também de déficit de pobreza):

$$
I_{a}=\frac{q}{N} \cdot \frac{Z-m}{m^{*}}
$$

onde $m^{*}$ é a renda média da comunidade. Notemos que $I_{a}$ é simplesmente a razão de defasagem de renda $I$ normalizada em termos da renda média da sociedade e pode ser interpretada como a percentagem da renda total da sociedade que é necessária para eliminar a defasagem de renda entre os pobres e a linha de pobreza.

Dentro dessa nova estrutura axiomática, compara-se agora as equações (4) e (11) e obtém-se: $A(Z, y)=2 /(q+1) N m *$. Portanto, dado que a mesma estrutura de pesos é mantida, via axioma $R$, a alternativa sugerida por Anand é escrita como:

$$
P_{a}=\frac{2}{(q+1) N m^{*}} \sum_{i=1}^{q}\left(Z-Y_{i}\right)(q-i+1)
$$

que difere do índice original (6) apenas no que concerne ao valor de $A$. Interpretativamente, entretanto, $P_{a}$ é bem diferente de $P$, visto 
que sendo agora dependente da renda total da sociedade, $P_{a}$ reflete até mesmo mudanças na renda das pessoas situadas acima da linha de pobreza, enquanto o índice $P$ é completamente insensível àquelas rendas. Alguns podem considerar $P_{a}$ superior a $P$ sob a alegação de que qualquer aumento de renda de alguém em $\mathrm{S}$, ceteris paribus, reflete-se de certa forma na redução da pobreza de toda a comunidade. ${ }^{13}$ A questão levantada por Sen $(1978,1979)$ em defesa do índice original $P$ é a de que $P_{a}$ leva em conta casos em que diminuições na defasagem de renda dos pobres vis-à-vis $Z$ podem ser compensadas por altos aumentos de renda dos não-pobres, situação em que $P_{a}$ não se modificaria.

Usando a mesma sistemática anterior, $P_{a}$ pode ser simplificado da seguinte forma:

$$
P_{a}=\frac{q}{N} \cdot \frac{1}{m^{*}}\left[Z-m\left(1-G_{P}\right)\right]
$$

Obviamente, quando $G_{P}=0$, isto é, quando não se leva em consideração a desigualdade de renda entre os pobres, $P_{a}$ se reduz a $I_{a}$. Notemos que o índice original de Sen pode ser reescrito como:

$$
P=\frac{q}{N} \cdot \frac{1}{Z}\left[Z-m\left(1-G_{P}\right)\right]
$$

Confrontando agora as equações (13) e (14), infere-se que:

$$
\begin{aligned}
& P_{a}=\frac{Z}{m^{*}} P \quad \text { e, portanto, } \\
& 0 \leq P_{a} \leq \frac{Z}{m^{*}}
\end{aligned}
$$

Suponha agora que a defasagem de renda $T$ seja expressa não como uma fração da renda total da comunidade, como sugerido por Anand, mas como uma fração de renda dos não-pobres:

$$
I_{f}=\frac{\sum_{i=1}^{q} g_{i}}{\sum_{i=q+1}^{N} Y_{i}}=\frac{q(Z-m)}{N m^{*}-q m}
$$

${ }^{13}$ Suponha, por exemplo, um aumento de renda de uma certa pessoa entre os nāo-pobres. $I_{a}$ diminui, e, conseqüentemente, $P_{a}$, ceteris paribus. 
Esta proposta, formulada por Fishlow (1972), implica um novo valor $A(Z, y): A(Z, y)=2 /\left(N m^{*}-q m\right)(q+1)$, cuja equação é obtida de (4) e (15).

Em virtude de que nenhuma alteração foi processada na estrutura de pesos definida pelo axioma $R$, o índice de pobreza de Fishlow $\left(P_{f}\right)$ pode ser escrito como:

$$
P_{f}=\frac{2}{\left(N m^{*}-q m\right)(q+1)} \sum_{i=1}^{q}\left(Z-Y_{i}\right)(q-i+1)
$$

ou, de forma simplificada:

$$
P_{f}=\frac{q}{N m^{*}-q m}\left[Z-m\left(1-G_{P}\right)\right]
$$

Notemos que quando $G_{P}=0$, implica naturalmente que $P_{f}=I_{f}$. De (17) e (14), resulta:

$$
P_{f}=\frac{Z}{m^{*}-\frac{q}{N} m} P \quad \text { e, portanto, } \quad 0 \leq P_{f} \leq Z /\left(m^{*}-H m\right)
$$

Observando-se a equação (15) podemos interpretá-la como representando o percentual da renda que deve ser redistribuído do grupo não-pobre para o conjunto dos pobres de forma que a defasagem de renda dos pobres seja reduzida a zero. Assim, o ônus teórico de erradicar a pobreza recai exclusivamente sobre os não-pobres, o que não acontece com o índice sugerido por Anand, no qual toda a sociedade é afetada, inclusive os pobres. ${ }^{14}$

A mesma crítica feita ao índice $P_{a}$ pode também ser dirigida à proposta de Fishlow. Quer dizer, um aumento na renda de alguém situado acima da linha de pobreza diminui $P_{f}$, malgrado o fato de que nenhuma redução na pobreza propriamente dita tenha efetivamente ocorrido.

\footnotetext{
${ }^{14}$ Suponhamos $I_{a}=0,08$. Dessa forma, sāo necessários $8 \%$ da renda total da sociedade (o que inclui também a participaçāo dos pobres) para eliminar a defasagem de renda entre pobres e a linha demarcatória de pobreza.
} 
É oportuno registrar que os índices $I_{a}$ e $I_{f}$ são passíveis de pequenas manipulações, de forma a permitirem interpretações variadas. Por exemplo, suponhamos que o propósito é "taxar" os estratos de mais altas rendas da sociedade, digamos, os $x \%$ mais ricos, de sorte que se transfira os recursos daí derivados, integralmente, para os pobres, zerando a defasagem de renda. Este novo índice, que chamaremos de $I_{x}$, pode ser escrito assim:

$$
I_{x}=\frac{q(Z-m)}{K_{x} N m^{*}}
$$

onde $K_{x}$ é a participação dos $x \%$ mais ricos da população na renda total da sociedade. ${ }^{15}$ Este índice indica, portanto, a potencialidade dos segmentos mais abastados da sociedade de contribuir para a erradicação da pobreza. Claro que $I_{x}$ sofre das mesmas deficiências de $I_{a}$ e $I_{f}$ no que concerne a eventuais alterações nos seus valores sem que o estado de pobreza da sociedade se tenha modificado.

Chamando agora de $K_{g}$ a proporção da renda nacional que é destinada aos gastos públicos, pode-se reescrever a expressão (18) de outra forma alternativa:

$$
I_{g}=\frac{q(Z-m)}{K_{g} N m^{*}}
$$

Neste caso, o índice $I_{g}$ representa o esforço governamental, em termos de gastos públicos, que seria teoricamente necessário para erradicar a pobreza.

Outra variante do índice de Sen — vamos denominá-la de $P_{t}$ foi proposta por Thon (1979). Desta feita a atenção se concentra em modificar o axioma $R$ de tal forma que a ponderação dada a cada pessoa de acordo com sua defasagem de renda em $S(Z)$, isto é, $v_{i}$, abranja agora a posição de todos os membros da comunidade $S$ e.não somente aqueles elementos de $S(Z): v_{i}=N-i+1$.

\footnotetext{
${ }^{15}$ Notemos, de passagem, que $N m^{*}$ pode representar a renda nacional total ou disponível, o produto nacional, a renda familiar etc., dependendo dos objetivos do estudo, da disponibilidade de dados etc.
} 
Com essa nova proposição para o sistema de pesos, o índice original de Sen assume a seguinte estrutura:

$$
P_{t}=A(Z, y) \sum_{i=1}^{q}\left(Z-y_{i}\right)(N-i+1)
$$

A fórmula final desta medida de pobreza foi apresentada por Thon (1979, p.439), como sendo:

$$
P_{t}=\frac{2}{(N+1) N Z} \sum_{i=1}^{q}\left(Z-Y_{i}\right)(N-i+1)
$$

o que implica a seguinte parametrização: $A(Z, y)=2 /(N+1) N Z$.

A fórmula de $P_{t}$ pode ser simplificada da seguinte maneira: somando e subtraindo $q$ ao segundo termo do somatório em (21), vem:

$$
P_{t}=\frac{2}{(N+1) N Z} \sum_{i=1}^{q}\left(Z-Y_{i}\right)(q-i+1)+\frac{2}{(N+1) N Z} \sum_{i=1}^{q}\left(Z-Y_{i}\right)(N-q)
$$

Portanto:

$$
P_{t}=H\left[I+(1-I) G_{P}\right]\left(\frac{q+1}{N+1}+2 H I\left(\frac{N-q}{N+1}\right)\right.
$$

Se considerarmos que normalmente são muito grandes os valores de $N$ e $q$, (23) pode sofrer uma simplificação adicional:

$$
P_{t}=H P+2 H I(1-H)
$$

cujos limites são zero e um, como em $P$.

A motivação subjacente a essa proposta de Thon deriva-se da existência de certa ambiguidade no índice $P$ de Sen quando há transferência de renda de uma pessoa pobre para outra menos pobre. Quando a menos pobre desafortunadamente ainda fica em $S(Z)$, a medida $P$ acusa invariavelmente um acréscimo. O mesmo já não se pode garantir de $P$ se a menos pobre cruza efetivamente a linha de 
demarcação. Dependendo do caso, $P$ pode até diminuir, o que seria uma incoerência.

Inspirado nesse caráter ambíguo de $P$, Thon propõe (21) que sempre aumenta quando há transferência de renda dos mais para os menos pobres (ou para os mais ricos). O eventual problema que transparece com a medida (21) é que ela sempre aumenta mesmo que a transferência redunde em uma diminuição do número de pobres (como, por exemplo, quando o beneficiário escapa de $S(Z)$ e cruza a linha de pobreza).

Ainda dentro do espírito original da medida sugerida por Sen, Takayama (1979) propõe como índice alternativo de pobreza o uso do coeficiente de Gini da distribuição de renda censurada (censored), truncada de cima pela linha de pobreza, em que a distribuição de renda censurada refere-se, nesse caso, à distribuição em que todas as rendas dos indivíduos acima da linha de pobreza são computadas como se fossem iguais ao nível de renda $Z{ }^{16}$ Assim, para um vetor de rendas censuradas:

$$
\begin{aligned}
& \hat{y}(Z)=\left(\hat{y}_{1}, \cdots, \hat{y}_{N}\right): \\
& \hat{y}_{i}=Y_{i} \quad \text { se } Y_{i}<Z, \quad \hat{y}_{i}=Z \text { se } y_{i}>Z
\end{aligned}
$$

Com base nesse conceito, Takayama formula uma nova axiomatização e propõe um índice, que denominaremos de $\hat{P}_{t}$, como a seguinte estrutura:

$$
\hat{P}_{t}=A(Z, \hat{y}) \sum_{i=1}^{N} \hat{g}_{i} v_{i}+B
$$

onde $A$ e $B$ são constantes de normalização, $\hat{g}_{i}$ é a defasagem de renda do indivíduo $i$ na distribuição censurada, dada pela diferença entre a renda média dessa distribuição e sua própria renda, e $v_{i}$ é a ponderação dada àquele desvio. Assim, $\hat{g}_{i}=\hat{m}-\hat{y}_{i}$, onde $\hat{m}$ é a

\footnotetext{
${ }^{16}$ Esse tipo de distribuição censurada foi utilizado por Langoni (1973) no seu controvertido trabalho, ao considerar que todos os indivíduos com renda superior a Cr\$ 9.997,00 teriam recebido somente Cr\$ 9.998,00. Veja.se, por exemplo, Costa (1977, p. 52 e passim).
} 
renda média da distribuição censurada:

$$
\hat{m}=\frac{1}{N} \sum_{i=1}^{N} \hat{y}_{i}=H m+(1-H) Z
$$

O axioma $R$ é modificado por Takayama exatamente como o fez Thon, isto é, considerando o peso $v_{i}$ associado à defasagem de renda $\hat{g}_{i}$ do indivíduo $i$ igual à sua colocação na ordenação de renda entre todos os membros da sociedade:

$\mathrm{Na}$ nova proposta é formulado um axioma adicional para especificar $B$ :

Axioma $Q$ : se não há ninguém abaixo da linha de pobreza, então $\hat{P}_{t}=0$.

Quando o número de pobres $q$ é zero, temos $\hat{m}=Z$ (vide equação 26) e $\hat{P}_{t}=B$. Mas pelo axioma $Q$, tal situação corresponde a $\hat{P}_{t}=0$. Portanto, $B=0$. De sorte que podemos reescrever (25) como:

$$
\hat{P}_{t}=A(Z, \hat{y}) \sum_{i=1}^{N}\left(\hat{m}-\hat{y}_{i}\right)(N-i+1)
$$

Para se determinar $A(Z, \hat{y})$, Takayama modifica o axioma $A$ original de Sen da seguinte maneira:

Axioma $\hat{A}$ : se todos os pobres têm a mesma renda zero, então $\hat{P}_{t}=H$.

Antes de utilizarmos esse axioma desenvolvamos primeiramente a equação (27):

$$
\hat{P}_{t}=A(Z, \hat{y})\left[-\frac{N \hat{m}(N+1)}{2}+\sum_{i=1}^{N} i \quad \hat{y}_{i}\right]
$$

Observemos que se todos os pobres têm rendas zero, então:

$$
\begin{aligned}
\sum_{i=1}^{N} i \hat{y}_{i} & =\sum_{i=q+1}^{N} i \hat{y}_{i} \\
& =(q+1) \hat{y}_{q+1}+(q+2) \hat{y}_{q+2}+\cdots+[q+(N-q)] y_{q+(N-q)}
\end{aligned}
$$


Sabendo-se, também, que na distribuição censurada rendas maiores do que $Z$ são computadas como sendo iguais a $Z$, tem-se:

$$
\sum_{i=1}^{N} i \hat{y}_{i}=\frac{N \hat{m}(N+q+1)}{2}
$$

Substituindo esta expressão em (28) e usando o axioma $A$, obtém-se:

$$
\hat{P}_{t}=1+\frac{1}{N}-\frac{2}{N^{2} \hat{m}} \sum_{i=1}^{N}(N-i+1) \hat{y}_{i}
$$

Mas esta equação não é outra senão aquela do próprio coeficiente de Gini da distribuição censurada (compare com a expressão (8)). ${ }^{17}$ Assim $\hat{P}_{t}=\hat{G}$, onde $\hat{G}$ é o coeficiente de Gini da distribuição de renda censurada.

$\hat{P}_{t}$ tem seus méritos como índice de pobreza - entre eles, por exemplo, está o fato de captar com maior ênfase a noção de privação relativa do que a própria medida proposta por Sen. O grande problema com $\hat{P}_{t}$ é que esse índice violenta o pressuposto básico de que a redução de renda de qualquer indivíduo em $S(Z)$ tem de, necessariamente, aumentar, ceteris paribus, o índice (Takayama 1979, p. 758; Sen 1978, p. 35; Sen 1979, p. 303). ${ }^{18}$ Este fenômeno decorre do fato de que uma pessoa abaixo da linha de pobreza pode eventualmente estar entre os relativamente mais ricos na distribuição censurada (com renda, por exemplo, acima da média dessa distribuição)

${ }^{17}$ Podemos perceber melhor agora porque Takayama impõe mais um axioma à formulaçāo do seu índice. $O$ índice original de Sen, $P$, corresponde ao coeficiente de Gini quando se substitui $q$ por $N$ e $Z$ por $m^{*}$ (Sen 1976, p. 255). Pelo axioma $A$ o Gini da populaçāo total é zero quando todas as pessoas têm a mesma renda $m^{*}(H=1$ e $I=O$ na equaçāo 14). Mas se todas as pessoas têm a mesma renda $m^{*}$ entāo $g=O$ na expressāo (1). Portanto, $A(Z, y)$ fica indeterminado na equaçāo (1). Assim, com apenas seus dois axiomas originais, Sen nāo fornece uma transposiçāo completa do seu índice de pobreza para um índice de desigualdade de renda. Daí porque Takayama complementa a axiomatizaçāo que liłe possibilita especificar $A(Z, y)$.

${ }^{18}$ Esse requisito é conhecido na literatura como o "axioma da monotonicidade" e foi originalmente proposto por Sen (1976, p. 219). Kakwani (1981), comentando sobre o trabal ho de Takayama, mostrou que esse requisito só nāo é cumprido nos casos em que a sociedade ten ha mais de $50 \%$ de sua populaçāo considerada pobre. 
e uma redução na sua renda diminui a desigualdade naquela distribuição e obviamente reduz o índice, ao invés de aumentá-lo.

O índice de pobreza $\hat{P}_{t}$ pode ainda ser simplificado através do uso da decomposição do coeficiente de Gini proposta por Bhattacharya \& Mahalanobis (1967) e adaptada por Takayama assim: $\hat{G}=G_{b}+w G_{p}$, onde $G_{b}$ é o coeficiente de Gini entre os pobres como um todo e os não-pobres na distribuição de renda censurada; $G_{p}$ é o coeficiente de Gini da distribuição de renda entre os pobres e $w$ é um peso associado a esse coeficiente. Takayama $(1979$, p. 756$)$ define $G_{b}$ e $w$ da seguinte maneira:

$$
G_{b}=H-\phi \quad \text { e } \quad w=H \phi
$$

onde $\phi=\frac{H m}{\tilde{m}}$, que é a participação da renda dos pobres na renda total. Desde que $1-\phi=\frac{Z(1-H)}{\hat{m}}$, então: ${ }^{19}$

$$
\hat{P}_{t}=H\left[(1-\phi) I+\phi \quad G_{p}\right]
$$

resultado este que guarda estreita semelhança com o índice $P$ de Sen. $\hat{P}_{t}$ está circunscrito ao intervalo fechado $[0,1]$, sendo igual a zero quando todos têm renda maior que $Z$ e sendo igual a um quando alguém acima da linha da pobreza detém toda a renda da comunidade.

Outra variante que modifica os axiomas originais de Sen foi sugerida por Foster, Greer \& Thorbecke (sem data). A motivação dessa nova proposta se alicerça no fato de o índice de Sen não ser passível de decomposição, de sorte a captar a influência de determinados grupos de pessoas ou famílias sobre a pobreza total. A medida de Foster, Greer \& Thorbecke (FGT) permite detectar a contribuição desses grupos no índice global. ${ }^{20}$

A fórmula geral do novo índice é dada por:

$$
P_{g}=A(Z, y) \sum_{i=1}^{q} g_{i}^{2}
$$

${ }^{19}$ Observemos que quando todas as rendas dos pobres sảo iguais a zero, a equação (30) se reduz a $\hat{P}_{t}=H$, que é exatamente o que foi estabelecido pelo axioma $A$. ${ }^{20}$ Além dessa importante característica, o índice de FGT satisfaz várias outras propriedades desejáveis de que deve ser dotado um índice agregado de pobreza. Vide, por exemplo, Rodgers \& Rodgers (1991) e Pyatt (1987). 
Notemos, a princípio, que o axioma $R$ é modificado de tal maneira que a dafasagem de renda do indivíduo $i$ é tomada como peso da própria defasagem: $v_{i}=g_{i}=Z-Y_{i}$

Implícito na derivação do índice de FGT está o axioma que estabelece que quando os pobres têm a mesma renda, $P_{g}=H I^{2}$. Quando os pobres têm a mesma renda, $A(Z, y)$ está determinado e o índice FGT pode ser escrito como:

$$
P_{g}=\frac{1}{N Z^{2}} \sum_{i=1}^{q}\left(Z-y_{i}\right)^{2}
$$

Tal expressão pode ser simplificada, reescrevendo-a da seguinte maneira:

$$
P_{g}=\frac{1}{N Z^{2}} \sum_{i=1}^{q}\left[(Z-m)+\left(m-y_{i}\right)\right]^{2}
$$

Sabendo-se que $(1-I)=\frac{m}{Z}$ e que o quadrado do coeficiente de variação $\left(C_{v}\right)$ entre os pobres é dado por:

$$
\begin{aligned}
& C_{v}^{2}=\frac{1}{q} \sum_{i=1}^{q} \frac{\left(m-y_{i}\right)^{2}}{m^{2}}, \quad \text { tem-se que } \\
& P_{g}=H\left[I^{2}+(1-I)^{2} C_{v}^{2}\right]
\end{aligned}
$$

Assim, como na medida $P$ de Sen, $P_{g}$ é função da incidência da pobreza $H$, da defasagem de renda $I$ e da desigualdade de renda entre os pobres $C_{v}$ (mensurada, desta feita, pelo quadrado do coeficiente de variação). Notemos, de passagem, que os índices $H, H I$ e $P_{g}$ são casos especiais do índice geral:

$$
P_{\alpha}=\frac{1}{N} \sum_{i=1}^{q}\left(g_{i} / Z\right)^{\alpha}
$$

para valores de $\alpha$ iguais a zero, 1 e 2 , respectivamente.

Também como em $P$, o campo de variação de $P_{g}$ se circunscreve entre zero, quando todas as rendas são maiores do que $Z$, e um, quando todas as rendas dos pobres forem zero. ${ }^{21}$

${ }^{21}$ Há uma crescente literatura utililzando o indice $P_{g}$. Vide, por exemplo, Besley \& Kanbur (1988), Ahmed, Khan \& Sampath (1991) Rodgers \& Rodgers (1991) e Greer \& Thorbecke (1986). 
Uma generalização do índice de Sen foi proposta por Kakwani (1980), a qual permite várias hipóteses acerca da questão de sensibilidade da medida à transferência de renda no conjunto da distribuição de renda. A fórmula geral de Kakwani é dada pela seguinte equação:

$$
P_{k}=\frac{q}{N Z \phi_{q}(h)} \sum_{i=1}^{q}\left(Z-y_{i}\right)(q-i+1)^{h}
$$

onde

$$
\phi_{q}(h)=\sum_{i=1}^{q} i^{h}
$$

Notemos que quando $h=O, \phi_{q}(O)=q$ e (34) se resume ao índice $H I$, dado em (5).

Se $h=1$, então $\phi_{q}(1)=\frac{q(1+q)}{2}$ e (34) reproduz exatamente o índice de Sen dado em (6).

Kakwani mostra que para valores de $h>1$, o índice $P_{k}$ se torna mais sensível à transferência de renda entre aqueles mais pobres. Ele sugere, assim, que o valor de $h$ deveria ser escolhido de acordo com o peso que a sociedade quer dar a essas transferências. ${ }^{22}$

Como se disse anteriormente, o índice de Sen corresponde ao coeficiente de Gini quando o número de pobres é substituído pelo total da população $N$ e a linha de pobreza $Z$ é trocada pela renda da comunidade $m^{*}$. Dentro deste prisma, Kakwani sugere uma medida semelhante a (21):

$$
P_{k}^{*}=\frac{1}{m^{*} \phi_{N}(h)} \sum_{i=1}^{q}\left(m^{*}-y_{i}\right)(N-i+1)
$$

onde

$$
\phi_{N}(h)=\sum_{i=1}^{q} i^{h}
$$

\footnotetext{
${ }^{22} \mathrm{~A}$ abordagem de Kakwani envolve certos problemas que vāo desde a violaçāo do "axioma da monotonicidade" (Thon 1983, p. 200) até a arbitrariedade da escol ha de $h$, cujo processo nāo garante necessariamente a sensibilidade requerida (Clark, Hemming \& Ulph 1981).
} 
Tabela 3.

Brasil: alguns indices de pobreza derivados

da proposta de Sen (anos selecionados)*

\begin{tabular}{ccccccc}
\hline ANOS & $I_{a}$ & $P_{a}$ & $I_{f}$ & $P_{f}$ & $P_{t}$ & $\tilde{P}_{t}$ \\
\hline 1960 & 0,093 & 0,125 & 0,107 & 0,142 & 0,259 & 0,067 \\
1970 & 0,070 & 0,096 & 0,078 & 0,107 & 0,249 & 0,053 \\
1980 & 0,019 & 0,032 & 0,020 & 0,034 & 0,136 & 0,018 \\
1983 & 0,064 & 0,091 & 0,071 & 0,101 & 0,259 & 0,049 \\
1986 & 0.019 & 0,031 & 0,020 & 0,033 & 0,138 & 0.017 \\
1987 & 0,049 & 0,070 & 0,052 & 0,074 & 0,245 & 0,039 \\
1988 & 0,047 & 0,069 & 0,051 & 0,138 & 0,321 & 0,026 \\
\hline
\end{tabular}

Fonte: Censos Demográficos de 1960, 1970 e 1980 e PNADs de 1983, 19861987 e 1988.

* Vide texto para formulacão e explicacão dos índices expostos nesta Tabela.

No caso de $h=1, P_{k}^{*}$ resulta no coeficiente de Gini da distribuição de renda de toda a comunidade, para altos valores de $N$.

A Tabela 3 reúne achados empíricos para o Brasil, em anos selecionados, de alguns índices de pobreza derivados da proposta original de Sen e que foram discutidos nesta subseção.

\subsection{Decomposição.}

Nos estudos sobre pobreza, é sempre muito útil decompor os índices utilizados, de sorte a captar a influência de seus componentes na medida global. Por exemplo, um índice de pobreza calculado para um país oferece uma idéia de severidade da pobreza como um todo mas não diz nada sobre qual a contribuição de cada região na medida global. Em outras aplicações, como nos estudos de determinados grupos envolvendo características étnicas, geográficas, sócio-econômicas (idade, sexo, tamanho da família etc.) é importante saber sobre a participação de particulares subgrupos no índice total.

Tomemos a população total de uma comunidade e a dividamos em $k$ regiōes mutuamente exclusivas. Identifiquemos as seguintes variáveis relativas à $j$-ésima região: $m_{j}^{*}=$ renda média dos pobres; $q_{j}=$ número de pobres; $N_{j}=$ população; $H_{j}=\frac{q_{j}}{N_{j}}=$ proporção da 
população pobre; $f_{j}=\frac{N_{j}}{N}=$ participação da região na população total.

Se ponderamos a incidência de pobreza em cada região ( pelas suas proporcōes populacionais $\left(f_{j}\right.$

$$
H=\sum_{j=1}^{q} f_{j} H_{j}
$$

Tomando agora as rendas médias dos pobres em cada uma das regiōes $\left(m_{j}\right.$ cada região em relação à população total $\left(\frac{q_{j}}{N}=f_{j} H_{j}\right)$, chega-se a:

$$
m=\frac{1}{H} \sum_{j=1}^{q} f_{j} H_{j} m_{j}
$$

As decomposiçōes (36) e (37) foram sugeridas por Kakwani (1980, p. 329) e têm a seguinte interpretação: o índice de pobreza $H$ da população total é igual á média aritmética ponderada da proporção da população pobre em cada região, sendo os pesos proporcionais à população de cada região. De maneira semelhante, a renda média dos pobres da população total, $m$, é uma média ponderada das rendas médias dos pobres em cada região, onde os pesos são dados pela percentagem da população pobre da cada região em relação ao total da população. ${ }^{23}$

Substituindo (36) e (37) em (11) e perfazendo algumas operaçōes, chega-se ao seguinte resultado:

$$
I_{a}=\frac{1}{m^{*}} \sum_{j=1}^{k} f_{j} m_{j}^{*} I_{a j}
$$

${ }^{23}$ Em correspondência privada, Rodolfo Hoffmann sugere uma fórmula mais simples e direta para $m$ :

$$
m=\frac{\sum_{i=1}^{k} q_{j} m_{j}}{\sum_{j=1}^{k} q_{j}}
$$

onde $m$ é uma média ponderada das rendas médias dos pobres em cada região, em que os pesos são o número de pobres em cada região. 
onde:

$$
I_{a j}=H_{j} \frac{Z-m_{j}}{m_{j}^{*}}
$$

Portanto, o índice de pobreza $I_{a}$ da população total de $S$ é igual a uma média ponderada dos índices $I_{a j}$ de cada região, onde os pesos são proporcionais à participação da renda de cada região em relação à renda total da comunidade ${ }^{24}$. A maior restrição que se pode fazer ao índice de defasagem de renda $I_{a}$ é que seu uso não considera a desigualdade de renda entre os pobres em $S(Z)$.

Uma decomposição que capta a desigualdade de renda entre os elementos em $S(Z)$ pode ser obtida através do índice proposto por FGT, apresentado anteriormente na equação (32). Relativamente ao $j$-ésimo grupo, tal índice tem a seguinte forma:

$$
P_{g j}=\frac{1}{N_{j} Z^{2}} \sum_{i=1}^{q_{j}}\left(Z-y_{i}\right)^{2}
$$

Se ponderarmos a medida dada em (39) pela participação populacional de cada grupo em relação ao contingente total da sociedade, obteremos o seguinte resultado para a expressão (32) (Foster, Greer \& Thorbecke sem data, pp. 9-10).

$$
P_{g}=\sum_{j=1}^{k} \frac{N_{j}}{N} P_{g j}
$$

Assim, o índice global $P_{g}$ pode ser decomposto nos índices $P_{g j}$ tomando como pesos as fraçōes populacionais dos grupos envolvidos na mensuração.

${ }^{24}$ Uma outra decomposição simples pode ser obtida para o índice $I$, dado em (3):

$$
I=\sum_{j=1}^{k} \frac{q_{i}}{q} I_{j}, \text { onde } I_{j}=\frac{Z-m_{j}}{Z}
$$

Desta feita a ponderação é feita pela proporção de pessoas pobres de cada região em relação ao total de pobres. 
Uma interessante proposta recente (Rodgers \& Rodgers 1991) enfatiza a questão da intensidade da pobreza (ao invés da quantidade ou proporção de pobres) nos vários subgrupos da população, relativamente à população total. A característica básica do novo índice é mensurar onde a pobreza é mais intensa e não, como é mais convencional, onde ela é mais extensa.

A nova medida, chamemo-la de $P I_{j}$, mensura a intensidade da pobreza no grupo $j$ em relação à pobreza total da população, sendo, portanto, uma medida comparativa de pobreza, por exemplo, $P I_{j}=2$ indica que a pobreza do grupo $j$ é duas vezes mais intensa do que a da população como um todo. $P I_{j}=0,6$ significa que a intensidade da pobreza em $j$ é $60 \%$ daquela registrada na população total. A expressão proposta para o índice é bem geral e pode ser dada por:

$$
P I_{j}^{\beta}=\frac{P_{j}^{\beta}}{P^{\beta}}
$$

onde $P^{\beta}$ é qualquer índice agregado de pobreza, desde que seja aditivamente decomponível (como $H, I a, P g$ etc) ${ }^{25} P_{j}^{\beta}$ é o nível de pobreza dentro do grupo $j$, medido em termos do índice sendo $P^{\beta}$. Por exemplo, se o índice sendo utilizado é o da incidência da pobreza, então:

$$
P I_{j}^{H}=\frac{H_{j}}{H}
$$

A interpretação de $P I_{j}^{H}$ é intuitiva: a intensidade da pobreza do grupo $j$, em termos de incidência da pobreza, é simplesmente a razão entre a incidência da pobreza do grupo $j$ e a incidência da pobreza da população como um todo.

${ }^{25}$ Qualquer índice aditivamente decomponível $P^{*}$ pode ser escrito sob a forma

$$
P^{*}=\sum_{j=i}^{k}\left(N_{j} / N\right) P_{j}^{*}
$$

onde $k$ é o número de grupos no qual a populaçāo é particionada; $N_{j}$ é o número de pessoas no grupo $j$ e $P_{j}^{*}$ é o nível de pobreza do grupo $j$ 
Outra variante, ainda inspirada no índice original de Sen, foi proposta como uma tentativa de manter a estrutura básica de $P$, onde a desigualdade de rendas entre os pobres é captada ${ }^{26}$. Para tanto, valemo-nos da suposição de que a desigualdade de renda dos pobres de toda a comunidade pode ser vista como uma proxy para a desigualdade de rendas entre os pobres em cada região ou grupo. A necessidade dessa suposição repousa no fato de o índice $P$ de Sen não ser decomponível (por região, ou grupo, exatamente porque o índice de Gini é um dos elementos de $P$. Isto é, não é possível achar um índice $G$ de Gini que seja uma soma ponderada de índices $G_{j}$ de Gini regionais).

Embora se possa encontrar várias evidências empíricas mostrando que o coeficiente de Gini entre os pobres é apenas ligeiramente diferente entre grupos ou regiōes, ${ }^{27} \mathrm{em}$ face das próprias características das populações afetadas pela pobreza, o certo é que a hipótese utilizada na derivação a seguir é restritiva e deve ser levada a efeito somente quando o pesquisador não dispõe de informações mais detalhadas.

Substituindo-se (36) e (37) em (10) e perfazendo as necessárias manipulações, o índice $P$ pode ser reescrito como:

$$
P=\sum_{j=1}^{k} f_{j} P_{j}
$$

onde $P_{j}$, o índice de pobreza da $j$-ésima região, é dado por:

$$
P_{j}=H_{j}\left[I_{j}+\left(1-I_{j}\right) G_{p}\right] \text {. }
$$

${ }^{26}$ Vide Romão (1982).

${ }^{27}$ Prado (1981) fornece evidência dessa assertiva para a região nordestina do Brasil, e Anand (1977) é a referência para a Malásia e Bhatty (1974) para a Índia. Romão (1981) calculou os seguintes coeficientes Gini, entre os pobres, para sete regiōes (IBGE-ENDEF) brasileiras: Rjo (0,278), São Paulo (0,275), Sul $(0,250)$, Minas Gerais e Espírito Santo $(0,277)$, Nordeste $(0,265)$, Distrito Federal $(0,286)$, Norte e Centro-Oeste $(0,258)$ e, finalmente, Brasil $(0,270)$. Fishlow (1980) e Dutta (1978) mostram que o índice de Gini das populações pobres do Brasil e Índia, respectivamente, não soíreram variaçōes de monta em termos temporais, o que dá uma idéia de estabilidade do índice para aquele segmento populacional nos dois países. Outros exemplos podem ainda ser encontrados na Tabela I-7 do Apêndice I em Romão (1990). 
Tabela 4.

Brasil e grandes regiōes.

Contribuição porcentual das grandes regiōes à formaçâo

de alguns indices de pobreza*

1888

\begin{tabular}{c|c|c|c|c|c|c|c}
\hline $\begin{array}{c}\text { Brasil e } \\
\text { grandes } \\
\text { regiöes }\end{array}$ & $\mathrm{I}$ & $I_{a}$ & $P_{a}$ & $P_{f}$ & $\mathrm{P}$ & $\mathrm{H}$ & $\mathrm{m}$ \\
\hline Brasil & 100,0 & 100,0 & 100,0 & 100,0 & 100,0 & 100,0 & 100,0 \\
Centro-Oeste & 6,4 & 7,5 & 6,5 & 6,4 & 6,2 & 6,6 & 6,7 \\
Norte & 2,6 & 2,8 & 2,6 & 2,6 & 3,0 & 2,7 & 2,7 \\
Nordeste & 42,1 & 28,3 & 40,5 & 40,6 & 38,9 & 38,9 & 37,1 \\
Sudeste & 35,5 & 47,0 & 36,6 & 36,6 & 40,7 & 37,6 & 38,8 \\
Sul & 13,3 & 14,5 & 13,7 & 13,7 & 11,2 & 14,1 & 14,6 \\
\hline
\end{tabular}

Fonte: PNAD de 1988.

* Vide texto para formulacão e explicacão dos índices decompostos e mostrados nesta tabela. A renda média dos pobres (m) foi considerada aqui como um índice de pobreza apenas para exemplificar a decomposição.

Visto deste prisma, o índice agregado de pobreza de $S$ é igual a uma soma ponderada de índices regionais de pobreza, onde os pesos são dados pela proporção da população de cada região.

Ainda fazendo uso da hipótese imbuída na derivação de (41), podemos aplicar o mesmo raciocínio para decompor outros índices com características semelhante como, por exemplo, os de Anand e Fishlow.

A Tabela 4 mostra, para o ano de 1988, a aplicação do processo decomposição para os diversos índices tratados nesta subseção. Nota-se a preponderância das regiões Nordeste e Sudeste na formação dos índices nacionais, não somente por conta da importância quantitativa dos próprios índices locais mas, também, pela influência das ponderações utilizadas.

\subsection{Dados agrupados.}

Um outro ponto importante sobre o índice de Sen é que a medida foi construída para utilização de dados individuais, conforme fica 
claro por uma simples inspeção à equação (6). Ademais, a estrutura dos pesos proposta no axioma $R$ refere-se à posição do indivíduo na ordenação de rendas em $S(Z)$, o que, aliás, forneceu a base teórica para o aparecimento do índice de Gini para dados individuais na derivação de $P$. De fato, a axiomatização denominada de Ordenação de Privação Relativa nada mais é do que uma maneira engenhosa de considerar a distribuição individual de rendas da população carente no índice de pobreza. O coeficiente de Gini apareceu naturalmente em $P$, por uma série de propriedades de que ele é possuidor, para captar a noção de privação relativa ${ }^{28}$.

A aplicação das fórmulas (6) ou (10), portanto, depende da disponibilidade de dados individuais de renda (ou outro atributo pertinente), os quais normalmente são de difícil acesso. Na ausência daquela informação, o pesquisador pode naturalmente lançar mão dos dados agrupados por intervalos de renda, que são mais comuns e via de regra publicados, e se perguntar de que maneira essas estatísticas poderiam ser aproveitadas para calcular o índice de pobreza de Sen.

Suponhamos novamente que as rendas individuais do vetor $y=$ $\left(y_{1}, y_{2}, \ldots, y_{N}\right)$ sejam ordenadas crescentemente, isto é, $y_{1}<y_{2}<$ $\ldots<y_{N}$. Suponhamos ainda que estes $N$ níveis de renda sejam agrupados em, digamos, $r$ intervalos de renda, $\left(y_{1}\right.$ a $\left.y_{2}\right),\left(y_{2}\right.$ a $\left.y_{3}\right), \ldots$ $\left(y_{r}\right.$ a $\left.y_{r+1}\right)$.

A freqüência relativa de qualquer classe de renda é dada por:

$$
f_{h}=\frac{N_{h}}{N}
$$

onde $N_{h}$ é o número de receptores de renda do $h$-ésimo de classe $(h=1,2, \ldots, r)$ e $N=N_{1}+N_{2}+\ldots+N_{r}$ é a população total. A freqüência cumulativa de indivíduos receptores até e inclusive o $h$-ésimo intervalo de renda é dada por:

$$
F_{h}=\sum_{s=1}^{h} f_{s}
$$

${ }^{28}$ Vide Romão (1990) 
Representemos a renda média do $h$-ésimo intervalo de classe por $\bar{y}_{h}$, quer dizer:

$$
\bar{y}_{h}=\frac{\sum_{N_{h}}^{N_{h}} y_{h i}}{N_{h}}
$$

onde $y_{h i}$ é o nível de renda do $i$-ésimo indivíduo no $h$-ésimo estrato. Uma vez que os indivíduos estão ordenados do mais pobre ao mais rico, a posição do indivíduo $i$ com renda $y_{h i}$ é dada por:

$$
\sum_{s=1}^{h} N_{s}-N_{h}+i
$$

Então, de acordo com (6), temos:

$$
P=\frac{2}{(q+1) N Z} \sum_{h=1}^{r^{*}} \sum_{i=1}^{N_{h}}\left(Z-y_{h i}\right)\left(q-\sum_{s=1}^{h}+N_{s}+N_{h}-i+1\right)
$$

onde $r^{*}<r$ refere-se ao número de intervalos de classe abaixo de $Z$. Se, agora, não considerarmos a desigualdade de renda dentro dos estratos, temos $y_{h i}=\bar{y}_{h}$ e podemos reescrever (42) como:

$P=\frac{2}{(q+1) N Z} \sum_{h=1}^{r^{*}}\left(Z-\bar{y}_{h}\right)\left(N_{h} \quad q-N_{h} \quad \sum_{s=1}^{h} N_{s}+N_{h}^{2}-\sum_{i=1}^{N_{h}} i+N_{h}\right)$.

Notemos, de passagem, que o termo $Z-\bar{y}_{h}$ é agora interpretado como a defasagem de renda do $h$-ésimo estrato, ficando claro, portanto, que estamos perdendo informaçōes sobre as influências individuais de renda em relação à linha de pobreza $Z$. Como:

$$
\sum_{i=1}^{N_{h}} i=\frac{1}{2} N_{h}\left(N_{h}+1\right)
$$

segue-se que (43) assume a forma:

$$
P=\frac{2}{(q+1) N Z} \sum_{h=1}^{r^{*}}\left(Z-\bar{y}_{h}\right) N_{h}\left[q-\sum_{s=1}^{h} N_{s}+\frac{1}{2}\left(N_{h}+1\right)\right] .
$$


Dividindo o numerador e o denominador de (44) por $N$, tal expressão pode também ser escrita como ${ }^{29}$ :

$$
P=\frac{2}{Z\left(H+\frac{1}{N)}\right.} \sum_{h=1}^{r^{*}} f_{h}\left(Z-\bar{y}_{h}\right)\left[H-F_{h}+\frac{1}{2}\left(f_{h}+\frac{1}{N}\right)\right]
$$

Em qualquer uma das expressões (44) ou (45), contudo, $P$ reduz-se ao produto $H I$ quando todos os pobres têm a mesma renda, já que os intervalos de classes abaixo de $Z$ deixam de ter significância, ficando todos os pobres englobados num só estrato $\left(r^{*}=1\right)^{30}$.

A perda de informaçōes individuais de renda acarreta uma subestimação do índice $P$, visto que as defasagens de renda dentro de cada classe são totalmente desprezadas. Como o esquema ponderativo de Sen agracia com pesos mais altos aquelas rendas mais baixas, seguese que o agrupamento necessariamente causa um viés para baixo na medida agregada $P$.

Submetido em maio de 1992. Revisado em fevereiro de 1993.

\section{Referências}

Ahluwalia, M.S. 1978. "Rural poverty and agricultural performance in India." Journal of Development Studies 14:298-323.

Ahmed, A.U., Khan, H.A. \& Sampath, R.K. 1991. "Poverty in Bangladesh: measurement, decomposition and intertemporal comparison." The Journal of Development Studies 27:48-63.

Alamgir, M. 1975. "Poverty inequality, and social welfare: measurement, evidence and policies." The Bangladesh Economic Review 3: $153-180$.

Altimir, O. 1978. La Dimensión de la Pobreza en America Latina. E/CEPAL/L. 180. Mimeo.

${ }^{29}$ A equação (45) foi proposta por Bhatty (1974, p. 300). O autor, contudo, apenas apresentou a expressão, não dando nenhum conteúdo indicativo de como ela poderia ter sido derivada e como poderia ser interpretada. Vide, também, Romão (1981; 1982).

${ }^{30} \mathrm{Na}$ equação (45), por exemplo, se todos os pobres têm a mesma renda $\left(y_{h i}=\right.$ $\bar{y}_{h}=m$ ), então $r^{*}=1$ e $f_{h}=F_{h}=\frac{q}{N}$, do que resulta $P=\frac{q}{N} \cdot \frac{Z-m}{Z}=H I$. 
Anand, S. 1977. "Aspects of poverty in Malaysia." Review of Income and Wealth 23: 1-16.

1983. Inequality and Poverty in Malaysia: Measurement and Decomposition. World Bank Research Publication.

Bhattacharya, N. \& Mahalanobis, B. 1967. "Regional disparities in household consumption in India." Journal of the American Statistical Association 62:143-161.

Bhatty, I.Z. 1974. "Inequality and poverty in India." In Srinivasan, T.N. \& Bardhan, P.K., eds., Poverty and Income Distribution in India. Calcutta: Statistical Publishing Society.

Blackorby, C. \& Donaldson, D. 1980. "Ethical indices for the measurement of poverty." Econometrica 48: 1053-1064.

Besley, T. \& Kanbur, R. 1988. "Food subsidies and poverty alleviation." The Economic Journal 98:701-719.

Camargo, J.M. \& Giambiagi, F., orgs. 1991. Distribuição de Renda no Brasil. Rio de Janeiro: Editora Paz e Terra.

CEPAL 1985. La Pobreza en América Latina: Dimensiones y Politicas. Estudios y Informes de la CEPAL, $\mathrm{n}$ ㅇ 54, Naciones Unidas.

Clark, S., Hemming, R. \& Ulph, D. 1981. "On indices for the measurement of poverty." The Economic Journal 91:515-526.

Cowell, F.A. \& Metha, F. 1982. "The estimation and interpolation of inequality measures." Review of Economic Studies 49:273-290.

Costa, R.A. 1977. Distribuição da Renda Pessoal no Brasil em 1970. Rio de Janeiro: IBGE.

da Mata, M. 1979. Concentração de Renda, Desemprego e Pobreza no Brasil. IPEA, Coleção Relatórios de Pesquisa no 41.

Dutta, B. 1978. "On the measurement of poverty in rural India." Indian Economic Review 13: 23-32.

ENDEF 1978. Estudo Nacional da Despesa Familiar. IBGE.

FAO/OMS 1971. Necessidades de Energia y Proteínas. OMS.

Fields, G.S. 1980. Poverty, Inequality and Development. Cambridge: Cambridge University Press.

Dutta, B. 1978. "On the measurement of poverty in rural India." Indian Economic Review 13: 23-32.

Fishlow, A. 1972. "Brazilian size distribution of income." American Economic Review 62:391-402. 
1980. "Who benefits from economic development? comment." American Economic Review 70:250-256.

Foster, J., Greer \& Thorbecke, E. (s/data). "A class of decomposable poverty measures." Working Paper no 243 , Department of Economics, Cornell University.

Greer, J. \& Thorbecke 1986. "A methodology for measuring food poverty applied to Kenya." Journal of Development Economics 24: 59-74.

Hagenaars, A.J.M. 1986. On the Concept of Poverty. Amsterdam: North Holland.

Hagenaars A. \& de Vos, K. 1987. "The definition and measurement of poverty." The Journal of Human Resources 23:211-221.

Hamada, K. \& Takayama, N. 1978. "Censored income distributions and the measurement of poverty." Bulletin de Institut International de Statistique 1:617-632.

Hoffmann, R. 1984. "Pobreza no Brasil." Série pesquisa, no 43, Departamento de Economia e Sociologia Rural, ESALQ.

1984a. "Estimation of inequality and concentration measures from grouped observations." Revista de Econometria 4: 5-21.

1985. "Distribuição de renda e pobreza entre as famnlias no Brasil, de 1980 a 1983." Revista de Economia Política 5:50-60. Mimeo. 1990. "Desigualdade e pobreza no Brasil, 1979-88."

Jaguaribe, H. et alli 1986. "Para um novo pacto social." Mimeo, IEPES, Rio de Janeiro.

Kakwani, N.C. 1980. Income Inequality and Poverty: Methods of Estimation and Policy Application. Oxford: Oxford University Press. metrica 49: 525-526.

Kapteyn, A., Kooreman, P. \& Willemse, R. 1987. "Some methodological issues in the implementation of subjective poverty definitions." The Journal of Human Resoucess 23: 222-242.

Kendall, M. \& Stuart, A. 1977. The Advanced Theory of Statistics Vol 1, Distribuition Theory, 4th edition. London: MacMillan. 
Knight, P. \& Moran, R. 1983. Brasil: Pobreza e Necessidades Básicas. Rio de Janeiro: Zahar Editores.

Krelle, W. \& Sherrocks, A.F., eds. 1978. Personal Income Distribution. Amsterdam: North Holland.

Langoni, C.G. 1973. Distribuição de Renda e Desenvolvimento Econômico do Brasil. Rio de Janeiro: Editora Expressão e Cultura.

Orshansky, M. 1965. "Counting the poor: another look at the poverty profile." Social Security Bulletin 28:3-29.

1969. "How poverty is measured." Monthly Labor Review 92: 37-41.

Piñera, S. 1979. "Definición, medición y análisis de la pobreza: aspectos conceptuales y metodologicos." E/CEPAL/PROY. 1/3. Mimeo.

Pyatt, G. 1987. "Measuring welfare, poverty and inequality." The Economic Journal 97: 459-467.

Prado, E.F.S. \& Macedo, R. B. 1980. "Dimensão regional da pobreza: um reexame do problema do Nordeste." FIPE/BNB/SUDENE.

Prado, E.F.S. 1981. "Crescimento econômico, pobreza e disbribuição de renda em países sub-desenvolvidos." Estudos Econômicos 11: 83-91.

Rawls, J. 1971. A Theory of Justice. Cambridge: Harvard University Press.

Rocha, S. 1990. "Indicadores de pobreza para as regiōes metropolitanas nos anos oitenta." Estudos Econômicos 20:439-460.

Rodgers, J.L. \& Rodgers, J.R. 1991. "Measuring the intensity of poverty among subpopulations." The Journal of Human Resouces 26: 339-361.

Romão, M.C. 1981. "Income distribution and poverty in Brazil." Ph.D. Dissertation, não publicada.

1982. "Índices de pobreza: alternativas, decomposição e uso com dados agregados." Estudos Econômicos 12:51-65.

1982a. "Issues in the concept of poverty." Texto para Discussão no 114, Departamento de Economia, Universidade Federal de Pernambuco. 
1983. "Consideraçōes sobre o conceito de pobreza." Revista Brasileira de Economia 36: 355-370.

1990. "Pobreza: conceito e mensuração." Relatório de Pesquisa, IPEA/INPES-PNPE, 289 p.

1991. "Distribuição de renda, pobreza e desigualdades regionais no Brasil." In Camargo, J.M. \& Giambiagi, F., orgs., Distribuição de Renda no Brasil. Rio de Janeiro: Editora Paz e Terra.

tribuição de renda e pobreza." Texto para Discussão no 270 , Departamento de Economia, Universidade Federal de Pernambuco.

Rowntree, S. 1991. Poverty: A Study of Town Life. London: Mac Millan.

Sen, A.K. 1973. "Poverty, inequality and unemployment: some conceptual issues in measurement." Economic and Political Weekly, Special Number 1457-1464.

1976. "Poverty: an ordinal approach to measurement." Econometrica 44:219-231.

1978a. "Ethical measurement of inequality: some diffculties." Personal Income Distribution. In. Amsterdam: North Holland.

1978. "Three notes on the concept of poverty." ILO WEP 2-23/WP 65.

1979. "Issues in the measurement of poverty." Scandinavian Journal of Economics 81:285-307.

1980. "Levels of poverty: policy and change." World Bank Staff.Working Papers no 401, The World Bank.

1981. Poverty and Famines: An Essay on Entitlement and Deprivation. Oxford: Clarendon Press Oxford.

Srinivasan, T.N. \& Bardhan, P.K., 1974. Poverty and Income Distribution in India. Calcutta: Statistical Publishing Society.

Szal, R.J. 1977. "Poverty: measurement and analysis." ILO WEP 2-23/WP 60.

Takayama, N. 1979. "Poverty, income inequality and their measures: professor Sen's axiomatic approach reconsidered." Econometrica 
47:749-759.

Thomas, V. 1978. "The measurement of spatial differences in poverty: the case of Peru." World Bank Staff Working Paper n으 273, The World Bank.

1982. "Differences in income, nutrition and poverty within Brazil." World Bank Staff Working Paper no 505, The World Bank.

Thon, D. 1979. "On measuring poverty." Review of Income and Wealth 25: 429-439.

Townsend, P. 1970. The Concept of Poverty. Heinemann.

Van Ginneken, W. 1980. "Some methods of poverty analysis: an application to iranian data, 1975-1976." World Development, 8: 639-646.

Van Praag, B.M.S., Goedhart, T. \& Kapteyn, A. 1979. "The poverty line: a pilot survey in Europe." Mimeographed, University of Southern California.

World Bank 1979. Brasil: Human Resources Special Report. The World Bank. 